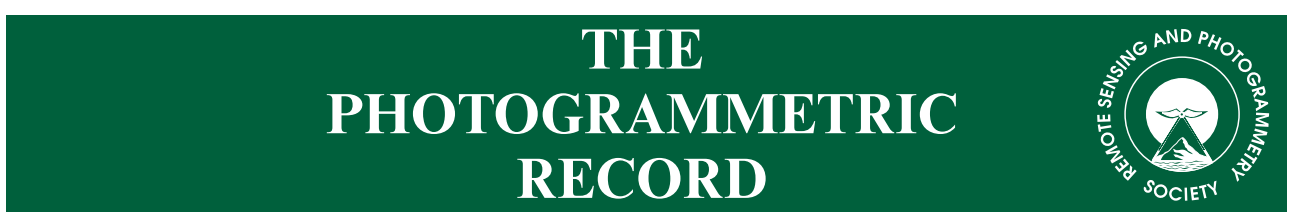

The Photogrammetric Record 30(149): 30-45 (March 2015)

DOI: $10.1111 /$ phor.12090

\title{
AN ALGORITHM FOR AUTOMATED ESTIMATION OF ROAD ROUGHNESS FROM MOBILE LASER SCANNING DATA
}

\author{
PANKAJ Kumar (pankajkumar@utm.my) \\ Universiti Teknologi Malaysia (UTM), Skudai, Johor, Malaysia \\ PAUL LewIs (paul.lewis@nuim.ie) \\ Conor P. McElhinney (conormce@cs.nuim.ie) \\ National University of Ireland Maynooth (NUIM), Maynooth, Ireland \\ Alias Abdul Rahman (alias@utm.my) \\ Universiti Teknologi Malaysia (UTM), Skudai, Johor, Malaysia
}

\begin{abstract}
Road roughness is the deviation of a road surface from a designed surface grade that influences safety conditions for road users. Mobile laser scanning (MLS) systems provide a rapid, continuous and cost-effective way of collecting highly accurate and dense $3 D$ point-cloud data along a route corridor. In this paper an algorithm for the automated estimation of road roughness from MLS data is presented, where a surface grid is fitted to the lidar points associated with the road surface. The elevation difference between the lidar points and their surface grid equivalents provides residual values in height which can be used to estimate roughness along the road surface. Tests validated the new road-roughness algorithm by successfully estimating surface conditions on multiple road sections. These findings contribute to a more comprehensive approach to surveying road networks.
\end{abstract}

KEYwORDS: elevation residual, lidar, mobile laser scanning, roughness, surface grid

\section{INTRODUCTION}

ROAD TRANSPORTATION PLAYS A VITAL ROLE in the progress and socio-economic growth of society, enabling the safe movement of goods, people and services. Roads are designed and built based on numerous design criteria, notably travel time, user comfort and convenience, fuel consumption, construction, cost and environmental impact (ETSC, 1997). A welldesigned and maintained route infrastructure assists in driver safety as well as in the efficient use of the overall network in terms of route navigation. Road networks should be developed and maintained by taking into account the vehicle, driver behaviour and road infrastructure elements (Treat et al., 1979); to date less consideration has been given to the 
latter factor (IRF, 2003). Analysis shows that accidents due to human error occur mostly at specific accident hotspots.

Road roughness can be considered an important factor that influences safety conditions for road users. It affects rolling resistance, ride quality, vehicle operating costs, fuel consumption and the safety of the road users (Sayers and Karamihas, 1998). Rough roads are often associated with some of the typical types of road accidents such as loss of control, running off the road and hitting fixed or moving objects (Bester, 2003). Several studies have indicated that the accident rate increases with increasing unevenness of the road surface (Ihs, 2004; Davies et al., 2005). Road roughness needs to be located, measured, recorded and characterised in a timely, cost-effective manner in order to schedule maintenance and ensure maximum safety conditions for road users. Mobile laser scanning (MLS) systems facilitate the acquisition of accurate and dense point-cloud data along route corridors in a rapid, continuous and cost-effective way. It is proposed that the spatially referenced 3D data can be used for reliable and precise estimation of roughness along a road surface. In Kumar et al. (2013), the current authors presented an automated algorithm for extracting road edge information from MLS data. This algorithm was applied to estimating road boundaries from lidar data, which are then used to identify the lidar points that belong to the road surface (Kumar et al., 2014). A priori knowledge of the road surface area facilitates a more efficient estimation of roughness along its surface. In this paper, an algorithm is presented for the automated estimation of road roughness from MLS data. This algorithm provides discrete estimation of road roughness in the form of standard deviation values of elevation residual points. These residual points are obtained after fitting a surface grid to the lidar points belonging to the road surface.

This paper is organised as follows. The next section reviews various existing approaches used for estimating roughness along the road surface. Following this, a stepwise description of the new road-roughness estimation algorithm is presented. Next, the algorithm is tested on various road sections. Finally, the road-roughness estimation results are discussed and conclusions drawn.

\section{LITERATURE REVIEW}

Road roughness is generally considered to be the deviation of the road surface from a designed surface grade that may develop as a result of road use, construction processes or a combination of these (Farias and de Souza, 2009). Several indices have been developed which are used to estimate roughness along a longitudinal profile of the road surface. These indices are computed as dynamic and geometrical values. Dynamic indices, such as the International Roughness Index (IRI), provide continuous estimation of the roughness based on a model that simulates a dynamic response of a standard vehicle moving along the road surface profile at a certain speed. Geometrical indices, such as the standard deviation of longitudinal roughness, provide discrete estimation of the roughness in the form of standard deviation values of relative elevation points measured along the road surface.

The IRI was developed by the World Bank in the 1980s in response to a requirement for a reference scale for road-roughness measurement (Sayers et al., 1986). This measure is used to provide a continuous estimation based on a model that applies a mathematical simulation of a standard vehicle moving along the road surface profile at a certain speed. The model uses a Quarter Car Simulator (QCS), as shown in Fig. 1.

The QCS consists of a sprung mass that represents the vehicle body and an unsprung mass that represents a wheel and half axle. The sprung mass is connected to the unsprung mass with a suspension spring and damper. The unsprung mass is in contact with the road 
KUMAR et al. An algorithm for automated estimation of road roughness from mobile laser scanning data

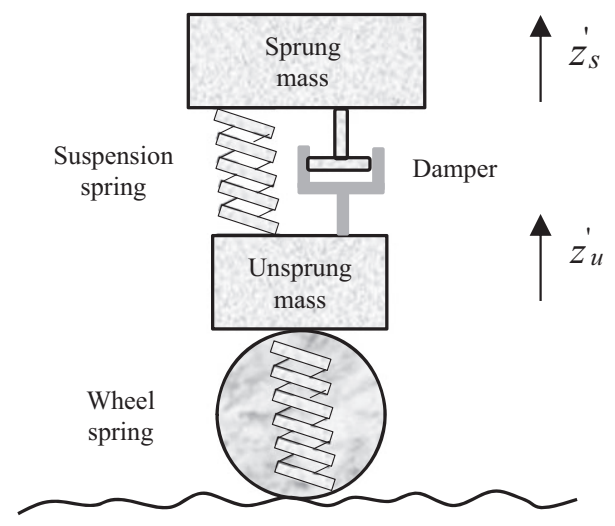

FIG. 1. Quarter Car Simulator.

surface using the wheel spring. During the simulation process, the QCS runs along the road surface profile at a constant speed, $V$. The roughness along the road surface generates $z_{s}^{\prime}$ and $z_{u}^{\prime}$ vertical speeds in the sprung and unsprung mass, respectively. The IRI value for a section of the road surface profile is estimated as

$$
\mathrm{IRI}=\frac{1}{L} \int_{0}^{x / V}\left|z_{s}^{\prime}-z_{u}^{\prime}\right| \mathrm{d} t
$$

where $L$ is a length of the road section in metres, $x / V$ is the time taken by the model to travel a certain distance $x$ and $\mathrm{d} t$ is a time increment. Thus, the IRI is an accumulation of a vertical displacement divided by the distance travelled by the vehicle that, in turn, provides the roughness scale. Its value is estimated in $\mathrm{m} / \mathrm{km}$ or inch $/ \mathrm{mile}$ units and ranges between 0 and $20 \mathrm{~m} / \mathrm{km}$. A $0 \mathrm{~m} / \mathrm{km}$ value of IRI represents a perfectly smooth road surface; a value of approximately $6 \mathrm{~m} / \mathrm{km}$ represents a moderate road roughness; and a value of $20 \mathrm{~m} / \mathrm{km}$ represents a bumpy, unpaved road surface (Paterson, 1987). One key advantage of using the IRI scale for the roughness measurement is its reliability, as it facilitates both repeatability and stability of results with respect to time (Sayers and Karamihas, 1998).

The standard deviation of longitudinal roughness provides discrete estimation based on elevation points that are measured at a $1.5 \mathrm{~m}$ interval along the longitudinal profile of the road surface as shown in Fig. 2 (Farias and de Souza, 2009).

These elevation points along the longitudinal profile are measured using straight-edge profilometers or laser profilers. The relative elevation $d_{i}$ for each point is computed as:

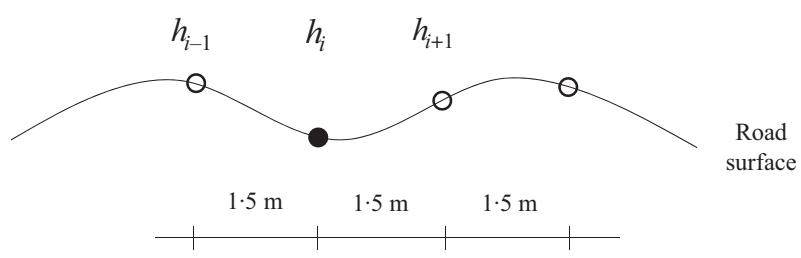

FIG. 2. Measurement of elevation points at a $1.5 \mathrm{~m}$ interval along the longitudinal profile of the road surface. 


$$
d_{i}=h_{i}-\frac{1}{2}\left(h_{i-1}+h_{i+1}\right)
$$

where $h_{i}, h_{i-1}$ and $h_{i+1}$ are the current, previous and next measured elevation values, respectively. A standard deviation of longitudinal roughness is estimated as

$$
\sigma=\sqrt{\frac{\sum_{i=1}^{n_{1}}\left(d_{i}-\overline{d_{i}}\right)^{2}}{n_{1}}}
$$

where $\overline{d_{i}}$ is the mean of the values and $n_{1}$ is the number of points.

Lidar data provides elevation values which have been used for estimating road roughness. Pattnaik et al. (2003) estimated grade and cross-slope parameters of a road segment from airborne laser scanning (ALS) data. Road boundaries were delineated using multi-resolution orthophotographs, a GIS (geographical information system) street database and a terrain model generated from ALS data. A plane was fitted to the lidar points belonging to a road using a linear regression model. Residuals for the grade and cross slope were then estimated by finding a goodness of fit of the regression plane with the lidar points. Zhang and Frey (2005) also presented a method for estimating the road grade and banking from ALS data using a linear regression model; however, road boundaries were extracted based on a priori knowledge of the road width instead of using a surface terrain model. Yu et al. (2007) presented an approach to characterise and visualise cracks along the road surface. In their approach, elevation values in each scanner line profile were thresholded to segment the road profiles; then coarse 3D surface models were reconstructed using cubic spline interpolation and median filter methods. The cracks in the coarse models were marked and were employed to reconstruct 3D models of higher detail. The final detailed models were used to estimate the geometry and shape of cracks along the road surface. Yen et al. (2010) analysed MLS data to produce digital terrain models of pavement surfaces. In one of their analyses, a linear plane was fitted to the data points for a 1 mile $(1.6 \mathrm{~km})$ road section and then the vertical offsets were calculated. Bitelli et al. (2012) described an approach for characterising the texture of the road surface using a 3D lasertriangulation scanner which works on the principle of calculating the distance from the laser scanner to the mapping object using a trigonometric triangulation method. In their work, they extended the mathematical expressions traditionally used for $2 \mathrm{D}$ texture indicators to ones applicable in a 3D context; they also introduced new surface- and volume-based texture indicators for characterising the road surface. Apart from the laser scanners, inertial measurement units (IMUs) mounted on mobile vehicles have also been used for measuring road roughness. Chin (2012) assessed the measurement of road profiles from a terrestrial laser scanning (TLS) system. This study investigated an optimal sampling interval required to filter the TLS data for smoothing out the noise without over-smoothing the data. The cross slope, cross correlation and IRI values were calculated from elevation attributes and were validated with values from road-profile instruments such as rods and levels, inclinometers and inertial profilers. Barsi et al. (2006) investigated the use of low-end IMUs for roughness estimation in which a strong correlation was found in between the roll values and the rough road surface. Later the same researchers (Kertesz et al., 2007) found correlated values of vertical acceleration, roll and pitch angles with the road quality and derived IRI values from the vertical acceleration. Wen (2008) presented a method to detect the road roughness from IMU data; a time-domain analysis of the data was performed to 
detect the location and magnitude of road bumps, while a frequency-domain analysis was used to estimate the road-texture information from the IMU data.

Some other approaches have also been developed for estimating roughness over soil and other terrain surfaces from lidar data. Zhang and Russell (2004) demonstrated a prototype system for estimating ground surface-roughness information using a combination of a camera and laser scanning system mounted on a mobile robotic platform. A multi-scale variance method was used over different ground surfaces to characterise an elevation profile at different spatial scales. Hollaus and Höfle (2010) investigated two approaches for estimating terrain roughness from full-waveform ALS data. In the first approach, an orthogonal regression plane was fitted to the lidar data and then the standard deviations of the residual elevation points were calculated. In the second approach, the roughness parameters were estimated from the echo-width attribute of lidar data, which provides information on the range distribution of scatterers. Both these approaches were found to be useful for extracting terrain-roughness information. However, the echo-width approach produced similarly patterned results even for moderate point densities. Diaz et al. (2010) characterised surface roughness in agricultural soil using MLS data. Lidar data was interpolated to create a surface grid model with a cell spacing of $1 \mathrm{~cm}$ which was used to estimate the surface roughness.

Lidar data provides elevation information which can be used to estimate road roughness without a requirement for any simulation process. Its ability to provide reliable information for estimating road roughness needs to be thoroughly explored. Unlike traditional methods, laser scanning systems can be used to provide spatially referenced roughness information along the road surface. Most approaches used to compute roughness indices are cumulative in nature. Lidar data can be used to provide localised roughness information along the longitudinal, as well as the transverse, profile of a road surface. Some of the methods developed for estimating road roughness from lidar data are based on fitting a regression plane and then computing elevation residuals. There is a need for a more robust surface-fitting approach that will provide an ideal representation of the road surface. A priori information of the road boundaries and its surface will facilitate the process of estimating road roughness. In the next section, the road-roughness estimation algorithm developed in this research is described.

\section{RoAD-ROUghness Algorithm}

An automated algorithm for extracting road edges from MLS data was presented in Kumar et al. (2013). The input consisted of $n$ lidar point-cloud datasets (30 m width; $10 \mathrm{~m}$ length; $5 \mathrm{~m}$ height), and also $n 10 \mathrm{~m}$ navigation data sections, to the road edge extraction algorithm developed by Kumar (2012). The dimensions of the input data sections were based on empirical tests as they impact on the efficiency of the process in terms of computational cost. The selection of a $30 \mathrm{~m}$ width ensured the inclusion of the road surface in the data; a $5 \mathrm{~m}$ elevation removed the impact of vertical objects along the route corridor; while a $10 \mathrm{~m}$ length was selected on the basis of the computational cost analysis. The input road sections were selected with an overlap of $2 \mathrm{~m}$ between them, which allows the batch processing of consecutive and overlapping road sections as required by the road edge extraction algorithm (Kumar et al., 2013). The algorithm outputs the road boundary, which is used to identify the lidar points that belong to the road surface. The road-roughness estimation algorithm is applied to the estimated road surface lidar points. The algorithm is based on the assumption that by fitting a surface grid to the lidar points belonging to the road surface and computing the elevation difference, the road roughness could be estimated. 


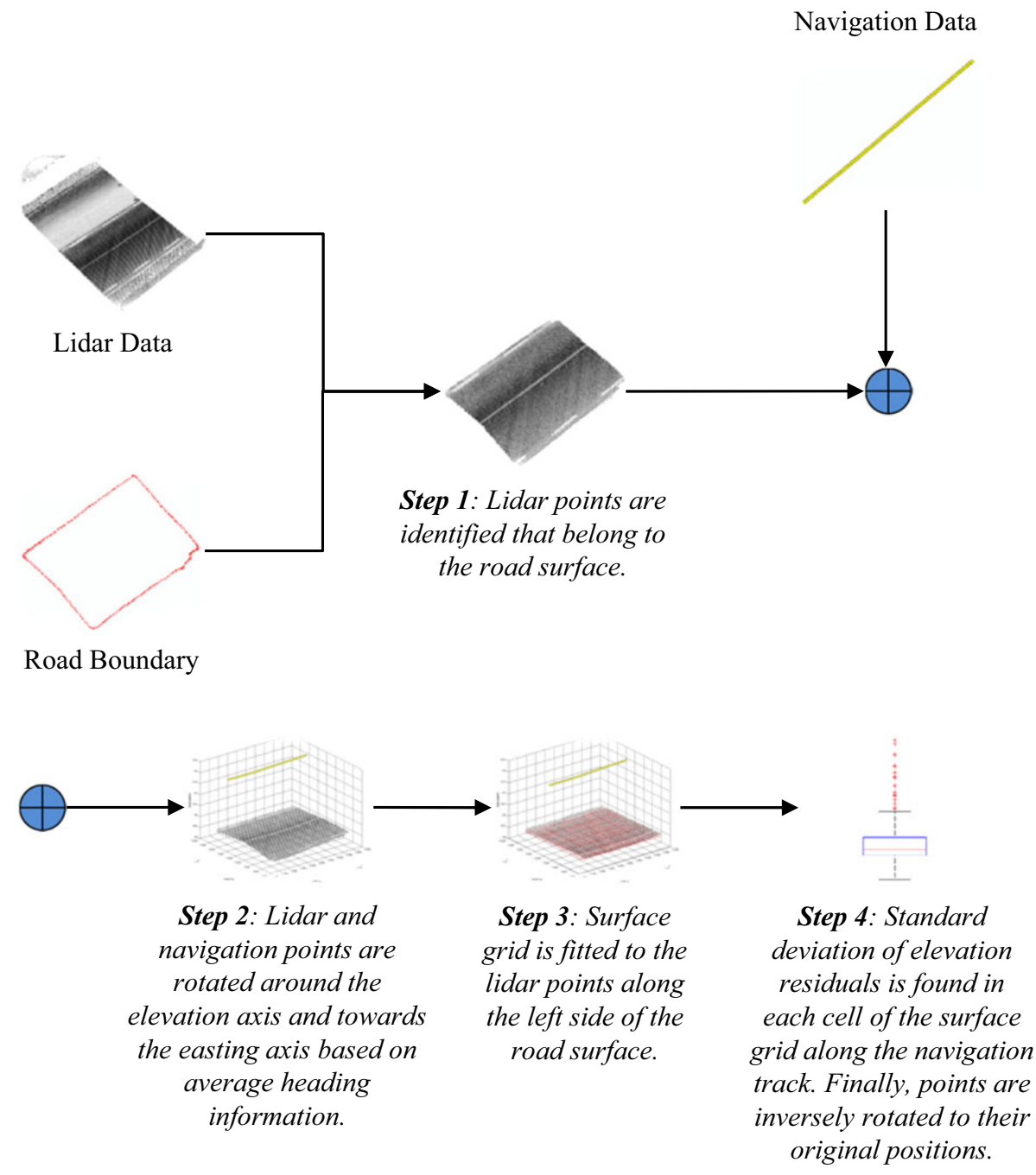

FIG. 3. Workflow of the road-roughness estimation algorithm.

A workflow of the road-roughness estimation algorithm is shown in Fig. 3. In the following sections, the algorithm's four processing steps are described in more detail.

\section{Step 1: Road Surface Estimation}

Lidar data provides the input and the road boundary is then estimated using the automated road edge extraction algorithm. In this first step of the road-roughness algorithm, the road boundary is used to identify the lidar points that belong to the road surface. A road boundary is overlaid on the lidar data such that the points outside the road boundary are removed, while inner points are retained to estimate the road surface (Kumar et al., 2014). 


\section{Step 2: Data Rotation}

In the second step of the road-roughness estimation algorithm, the lidar and navigation points are rotated around the elevation axis and towards the eastings axis. This rotation is carried out to assist the process of fitting a surface grid to the lidar points described in the next section. Both the lidar and navigation points are rotated through an angle $\varphi$, which is calculated from the average heading angle $\theta$ of the mobile van (Kumar, 2012; Kumar et al., 2013).

\section{Step 3: Surface Grid}

In the third step, the random sample consensus (RANSAC) algorithm is used to fit a surface grid to the lidar points. The RANSAC algorithm provides a robust fitting of a model to input points in the presence of outliers (Fischler and Bolles, 1981). Unlike conventional model-fitting techniques that use as many data points as possible to obtain an initial solution, the RANSAC algorithm uses the smallest set of initial data points required to fit a model and enlarges this set with compatible data points (Derpanis, 2010). Here $m=3$ is the number of random points that are required to fit an initial plane using a least squares model $l$. The least squares model is fitted to the points based on minimising the sum of the squares of the residuals, which are the differences between the actual points and the fitted points. The model $l$ is used to estimate points in the dataset which are within an error tolerance parameter $\varepsilon$. These estimated data points are called consensus points. If the number of consensus points is equal to, or larger than, a threshold $t$, then a new least squares model $l^{*}$ is fitted to these points. Otherwise, the whole process is repeated beginning with a random selection of $m$ points. After some pre-set number of iterations $k$, if the number of consensus points, equal to or larger than $t$, is not found, then the model fitted with the largest number of consensus points is accepted.

The RANSAC algorithm uses three specified parameters: $\varepsilon, k$ and $t$. The value of $\varepsilon$ is calculated experimentally by repeatedly fitting a model to the randomly selected data points a number of times and then measuring the error between the fitted model and the data points for each repetition. The value of $\varepsilon$ is then set as the sum of the mean and standard deviation of the measured errors (Fischler and Bolles, 1981). This allows $\varepsilon$ to be set automatically. If $p$ is the probability that any selected data point is within the error tolerance value $\varepsilon$, and $q$ is the desired probability for getting a good set of data points, then the value of $k$ is calculated as (Fischler and Bolles, 1981):

$$
\left(1-p^{m}\right)^{k}=(1-q)
$$

and thus

$$
k=\frac{\log (1-q)}{\log \left(1-p^{m}\right)} .
$$

The value of the $t$ parameter is calculated as (Collins, 2007):

$$
t=p n_{1}
$$

where $n_{1}$ is the number of data points. The fitted surface grid is a representative of what the ideal road surface should be. This surface is used to measure the elevation residuals along 


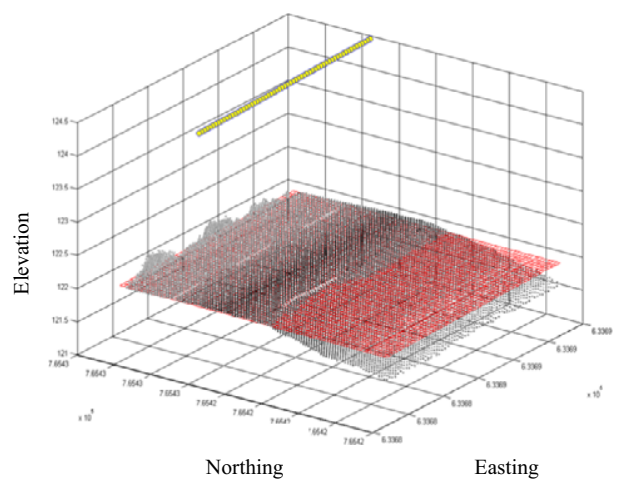

(a)

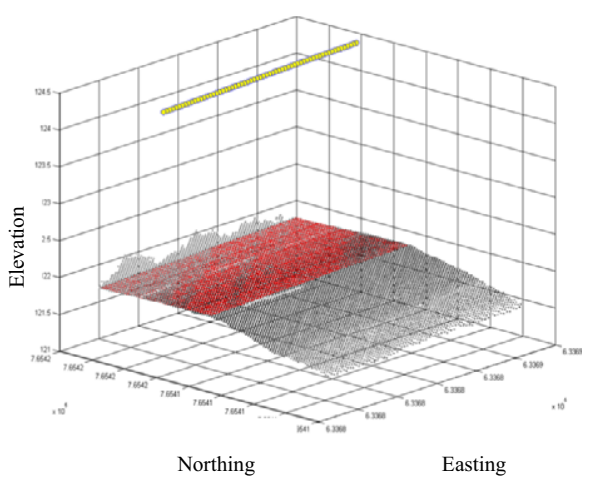

(b)

FIG. 4. Surface grid represented with red is fitted to the lidar points that belong to: (a) the whole road surface; (b) the left side of the road surface. Navigation points are represented in the upper part in yellow.

the navigation track described in the final step. A surface grid is not fitted to the lidar points that belong to the complete road surface as it does not provide an accurate representation of the road surface due to its non-planar shape, as can be seen in Fig. 4(a).

The lidar points are divided into the left and right sides of the road surface based on their rotated northing values. It is assumed the centre of the road is in the middle of the extracted road surface. Using the road boundaries from the road edge extraction algorithm, the road can be easily split into two parts (left and right). A surface grid is fitted to the lidar points belonging to the left side of the road surface as shown in Fig. 4(b). The size of the cell in the surface grid is selected based on the surface area of the footprint of the mobile van's wheel that comes into contact with the road surface. This cell size is chosen to measure the roughness experienced at each discrete instant of the vehicle's movement over the road surface.

\section{Step 4: Road Roughness}

In the final step of the algorithm, the elevation residual values are found by calculating the difference between the elevation of each lidar point and its respective surface grid point. A standard deviation of the elevation residuals in each cell along the navigation track of the mobile van is determined as:

$$
s=\sqrt{\frac{1}{n_{2}} \sum_{i-1}^{n_{2}}\left(z_{i}-\bar{z}\right)^{2}}
$$

where

$$
\bar{z}=\frac{1}{n_{2}} \sum_{i=1}^{n_{2}} z_{i}
$$

and $z$ is the residual and $n_{2}$ is the number of residuals in each cell. The estimated standard deviation values provide roughness information along the longitudinal road surface. Finally, 
the lidar points are inversely rotated to their original position along the road surface. In the next section, experiments using the road-roughness estimation algorithm on various road sections are presented.

\section{EXPERIMENTATION}

Four sections of road were selected to test the road-roughness estimation algorithm. These four sections covered $120 \mathrm{~m}$ of urban and national primary roads. These road sections were selected to demonstrate the effectiveness of the algorithm to estimate the roughness present along their surfaces. The processed data was collected using the experimental Platform (XP-1) MLS system which has been designed and developed at the National University of Ireland Maynooth (NUIM) (Kumar, 2012). Fig. 5 shows the four selected road sections: Figs. 5(a) and (b) show the first and second $10 \mathrm{~m}$ urban roads; Figs. 5(c) and (d) depict the third and fourth $50 \mathrm{~m}$ urban and national primary roads.

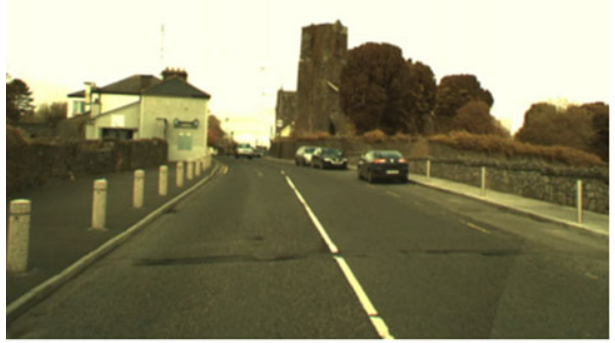

(a)

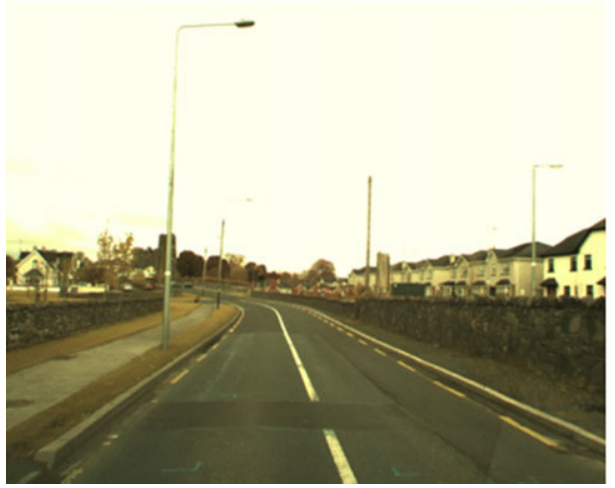

(c)

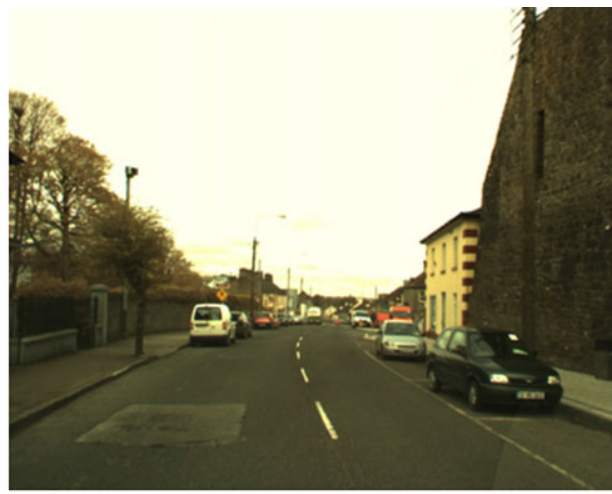

(b)

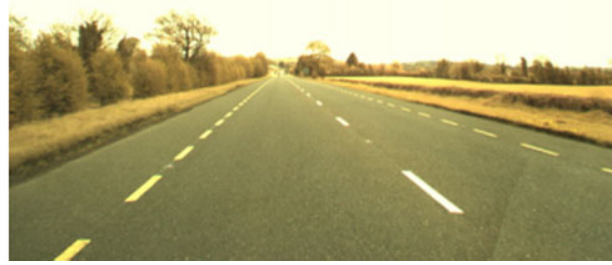

(d)

FIG. 5. Digital image of selected road sections: (a) first $10 \mathrm{~m}$ section of urban road; (b) second $10 \mathrm{~m}$ section of urban road; (c) third $50 \mathrm{~m}$ section of urban road; (d) fourth $50 \mathrm{~m}$ section of national primary road. 
To process each $10 \mathrm{~m}$ road section, there is one $(n=1) 30 \mathrm{~m} \times 10 \mathrm{~m} \times 5 \mathrm{~m}$ section of lidar data and also one $(n=1) 10 \mathrm{~m}$ section of navigation data. To process each $50 \mathrm{~m}$ road section, $n=6$ sections of lidar data covering $30 \mathrm{~m} \times 10 \mathrm{~m} \times 5 \mathrm{~m}$ were used together with $n=6$ sections, $10 \mathrm{~m}$ long, of navigation data. In the third and fourth road sections, there was an overlap of $2 \mathrm{~m}$ between adjacent lidar sections (Kumar et al., 2013). In order to avoid the dual estimation of roughness in the overlapping portions, the duplicate points in the first of the two overlapping lidar sections was removed. Thus, in the first and second lidar sections, the duplicate points in the first section were removed; in the second and third lidar sections, the duplicate points in the second lidar section were removed, and so on.

The road-roughness estimation algorithm was applied to the four selected road sections. Parameter $\varepsilon$ was estimated experimentally in the algorithm. Probabilities of $p=0.50$ and $q=0.99$ were selected, meaning there was a $50 \%$ likelihood of selecting any data point within the error tolerance and a $99 \%$ probability of producing a good set of points. Using these two probabilities and $m=3$ in equation (5), the number of iterations $k$ was calculated as 35 . The threshold parameter $t$ was computed by multiplying the number of points $n_{1}$ in the respective lidar section by the probability $p$ using equation (6). The values of the $\varepsilon$ and $t$ parameters used for fitting surface grids to the lidar sections are shown in Table I.

The $\varphi$ angle was calculated as $90^{\circ}-\theta$ in each navigation section of the road sections. The length and width of each cell in the surface grid was 0.215 and $0.18 \mathrm{~m}$, respectively. These values were estimated based on the measured surface area of the footprint of the mobile van's wheels that come into contact with the road surface. The fitted surface grids and lidar points along the navigation track of the tested road sections are shown in Fig. 6.

Finally, a standard deviation of the elevation residual values was calculated in each cell along the navigation track in the various road sections. The roughness along the right side of the road surface was not estimated due to a lower point density of the lidar data along that side. This was due to the use of a single laser scanner in the XP-1 system during the data acquisition process, which led to the acquisition of lidar data with a lower point density along the right side of the road section compared with its left side (Kumar, 2012). In the tested road sections, the average of the lidar point density samples collected over the left and right sides of the urban road section was $880 \cdot 66 / \mathrm{m}^{2}$ and $142 \cdot 18 / \mathrm{m}^{2}$, respectively, while the average of the point density samples collected over the left and right sides of the

TABLE I. Parameters $\varepsilon$ and $t$ used in the road-roughness estimation algorithm.

\begin{tabular}{|c|c|c|c|c|c|c|c|c|}
\hline \multirow[t]{3}{*}{ Lidar sections } & \multicolumn{8}{|c|}{ Road sections } \\
\hline & \multicolumn{2}{|c|}{ First } & \multicolumn{2}{|c|}{ Second } & \multicolumn{2}{|c|}{ Third } & \multicolumn{2}{|c|}{ Fourth } \\
\hline & $\varepsilon(m)$ & $t$ & $\varepsilon(m)$ & $t$ & $\varepsilon(m)$ & $t$ & $\varepsilon(m)$ & $t$ \\
\hline 1 & 0.03 & 16495 & 0.02 & 23868 & $0 \cdot 08$ & 6986 & $0 \cdot 02$ & 19642 \\
\hline 2 & & & & & $0 \cdot 06$ & 10174 & $0 \cdot 04$ & 20665 \\
\hline 3 & & & & & 0.02 & 7767 & 0.03 & 20662 \\
\hline 4 & & & & & 0.07 & 7860 & $0 \cdot 01$ & 20399 \\
\hline 5 & & & & & 0.03 & 9392 & 0.05 & 20969 \\
\hline 6 & & & & & $0 \cdot 04$ & 11389 & 0.03 & 24327 \\
\hline
\end{tabular}


KuMAR et al. An algorithm for automated estimation of road roughness from mobile laser scanning data

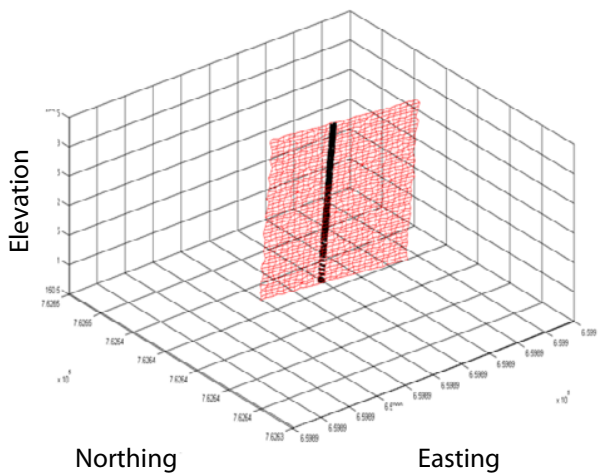

(a)

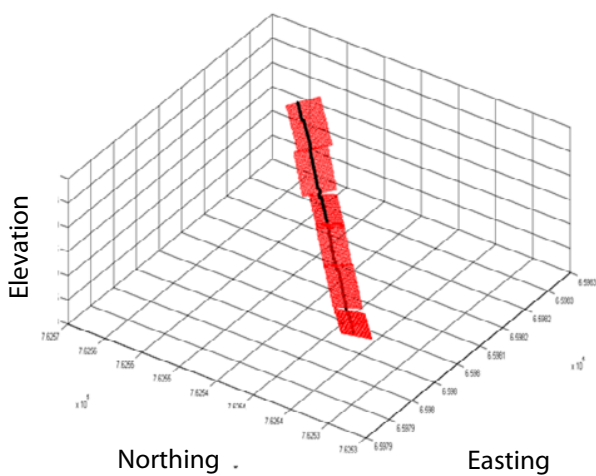

(c)

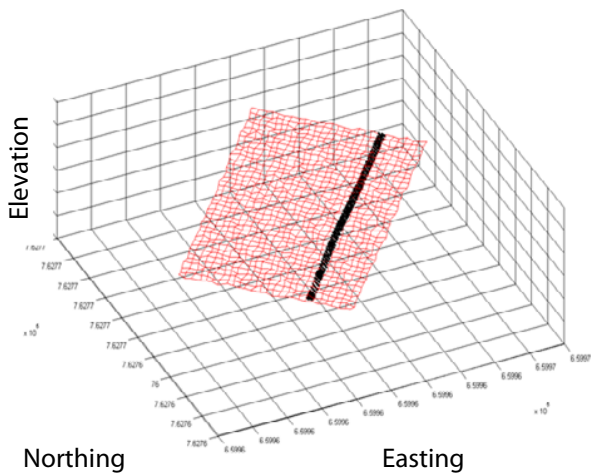

(b)

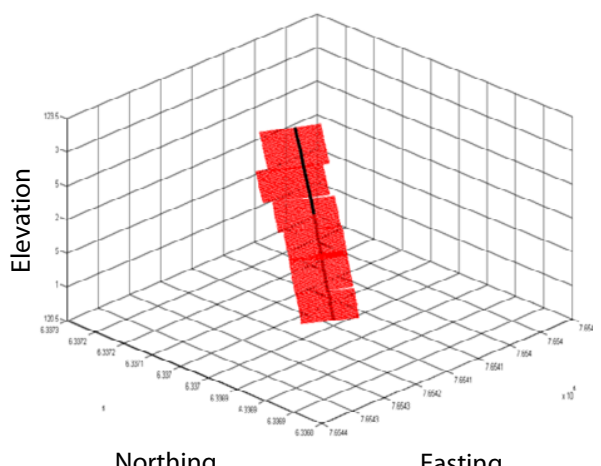

(d)

FIG. 6. Fitted surface grid is represented in red and lidar points along the navigation track are represented in black in the (a) first, (b) second, (c) third and (d) fourth road sections.

national primary road section was $1031 \cdot 75 / \mathrm{m}^{2}$ and $45 \cdot 84 / \mathrm{m}^{2}$, respectively (Kumar et al., 2013).

\section{RESUlts AND Discussion}

Surface deviation maps were generated for the tested road sections to create a visual representation of the roughness present along their surfaces, as shown in Fig. 7. The surface deviations were calculated as the elevation residuals between the lidar points and the fitted surface grid points. The deviation maps were generated with red and blue representing the highest and lowest values, respectively, at their extreme ends. In the first, second and third road sections, there was more variation on the surface, while in the fourth road section the variation was less. In the surface deviation maps of the first and second road sections, linear and square patterns were observed, respectively, which corresponded to the roughness present along their surfaces in the real-world environment as shown in Figs. 5(a) and (b). These patterns observed in the surface deviation maps 


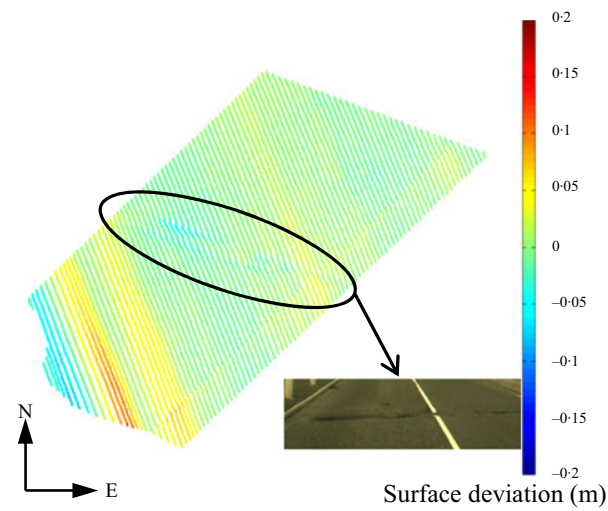

(a)

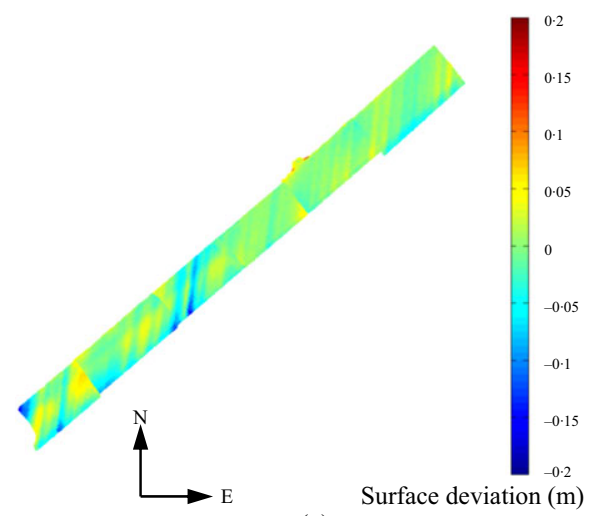

(c)

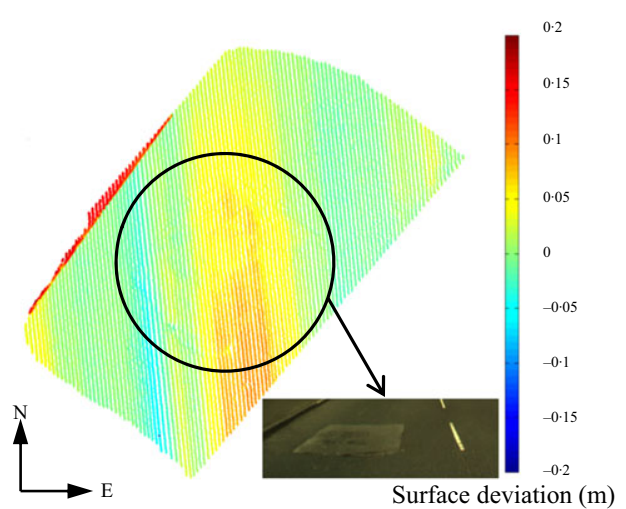

(b)

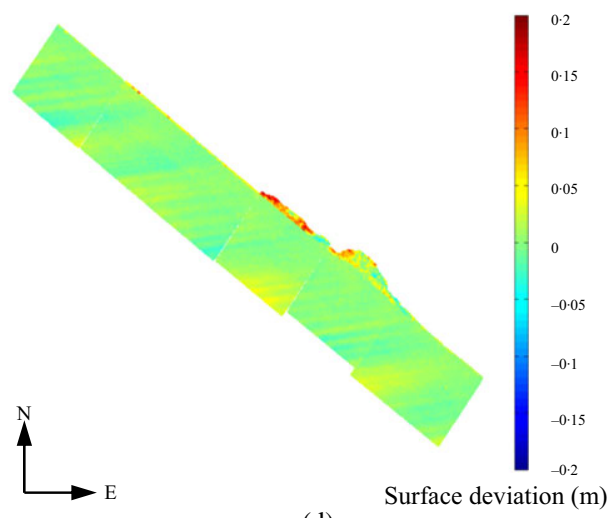

(d)

FIG. 7. Surface deviation maps for the (a) first, (b) second, (c) third and (d) fourth road sections. Red and blue represent the highest and lowest values, respectively; green represents small deviations.

were validated by matching their geographical eastings and northings coordinates with the coordinates in the digital images.

Box plots of the standard deviations of the elevation residual points along the navigation track in the tested road sections are shown in Fig. 8. A statistical analysis was also completed of the standard deviation values calculated for the four road sections as shown in Table II. Considering just the minimum and maximum values, the best results were produced for the fourth road section, while results were found to be poorest for the third road section. The mean and median values were lowest for the fourth road section, while they were highest for the second road section. Similarly, the number of outliers were least for the fourth road section but highest for the first road section. These values indicate a smoother surface in the fourth road section (along a national primary road) and uneven surface at some of the points in the first, second and third road sections (in urban areas). There is also a correlation between the calculated standard deviation and the IRI values, which allows the quantification of the estimated road roughness into standard reference-scale values. However, this comparison was not carried out as it was outside the scope of this study. 
KUMAR et al. An algorithm for automated estimation of road roughness from mobile laser scanning data

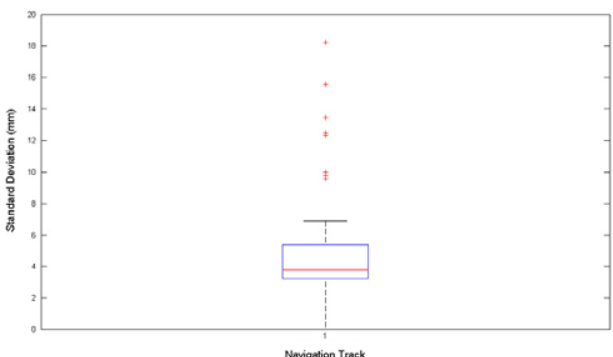

(a)

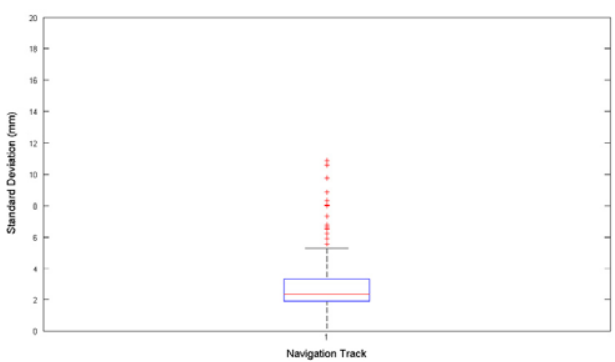

(c)

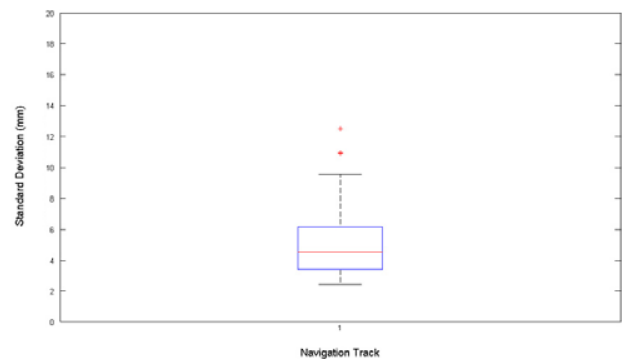

(b)

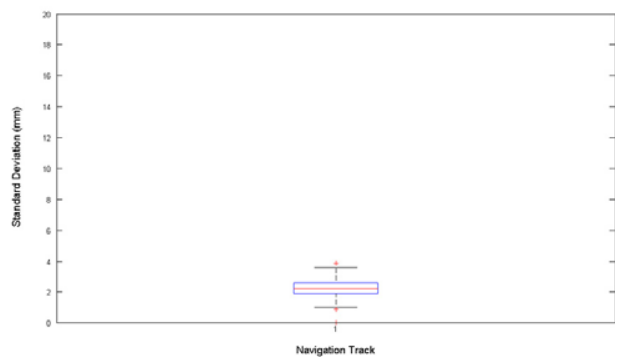

(d)

FIG. 8. Box plot of the standard deviations of the elevation residual points along the navigation track in the (a) first, (b) second, (c) third and (d) fourth road sections.

TABLE II. Statistical analysis of the standard deviations of the elevation residual points along the navigation track in the first, second, third and fourth road sections.

\begin{tabular}{lcccc}
\hline & \multicolumn{3}{c}{ Road sections } \\
\cline { 2 - 5 } & First & Second & Third & Fourth \\
\hline Minimum (mm) & 0 & 2.38 & 0 & 0 \\
Maximum (mm) & $18 \cdot 22$ & 12.53 & 20.14 & 3.87 \\
Lower adjacent (mm) & 0 & 2.38 & 0 & 1.01 \\
Upper adjacent (mm) & 6.92 & 9.56 & 5.32 & 3.55 \\
25th percentile (mm) & 3.17 & 3.38 & 1.88 & 1.88 \\
75th percentile (mm) & 5.41 & 6.18 & 3.29 & 2.56 \\
Mean (mm) & 5.23 & 5.25 & 2.88 & 2.18 \\
Median (mm) & 3.76 & 4.54 & 2.31 & 2.19 \\
Outliers (\%) & 17.39 & 8.11 & 7.83 & 3.91 \\
\hline
\end{tabular}

\section{CONCLUSION}

In this paper a novel approach for estimating road roughness from MLS data has been presented. The approach is based on the assumption that fitting a surface grid to the road surface lidar points provides elevation residual values that can be used for estimating road roughness. This surface-fitting process is an attempt to automatically reconstruct an ideal road surface. The successful estimation of roughness from the four tested road sections validates the algorithm. These research findings can be used to provide rapid, cost-effective 
and comprehensive information to the road authorities in order to schedule maintenance and ensure maximum safety conditions for road users.

Further research is required to investigate optimal values of the parameters used in the RANSAC algorithm in order to fit a surface grid that would best represent an ideal road surface. The underlying point density of the lidar data will affect the surface grid fitting. The limitations of point density on the surface grid fitting approach needs to be investigated to recommend a point density for different road surface grades. There is also a need to study the effect of different scanner setting, configuration and vehicle operating speed on roadroughness measurement results. The use of more than one laser scanner or a double-pass approach in which the vehicle is driven back and forth along the road, can be employed to acquire uniform and dense point clouds along both sides of the road section (Kumar et al., 2013). This will allow the estimation of the roughness along both the left and right sides of a road section. In comparison with the traditional road-roughness measurement methods, this algorithm has the additional benefit of estimating the spatially referenced and localised roughness information along the road surface. Unlike QCS and longitudinal roughness standard deviation methods, it can provide an estimate of the roughness across any track on the road section including the transverse road profile. The algorithm, through the use of lidar technology, provides an accurate estimation of road roughness without using any simulation model. One shortcoming of this road-roughness estimation methodology, however, is that it may not produce a continuous measure of roughness similar to the conventional QCS method. One solution might be to use a sliding surface grid technique in which the grid could be modelled to slide along the road surface. The standard deviation values could be estimated at each instant which could provide a dynamic estimation of the roughness along the road surface. Direct comparison with the international standard IRI scale is required to aid interpretation of the road-roughness estimation in these experiments. Additional research is required to find a correlation between the calculated standard deviation and the IRI values along the road surface. This will allow the estimated road roughness to be quantified against this globally accepted IRI scale.

\section{ACKNOWLEDGEMENTS}

The research presented in this paper was initially funded by the Irish Research Council (IRC) Enterprise Partnership Scheme and Strategic Research Cluster grant 07/SRC/I1168 of Science Foundation Ireland (SFI) under the National Development Plan. The research was continued at Universiti Teknologi Malaysia (UTM) (Vot No. 01E64). The authors gratefully acknowledge this support.

\section{REFERENCES}

Barsi, A., Lovas, T. and Kertész, I., 2006. The potential of low-end IMUS for mobile mapping systems. International Archives of Photogrammetry, Remote Sensing and Spatial Information Sciences, 36(1): 423426.

Bester, C. J., 2003. The effect of road roughness on safety. Proceedings of Transportation Research Board (TRB) Annual Meeting, Washington, DC, USA. 23 pages.

Bitelli, G., Simone, A., Girardi, F. and Lantieri, C., 2012. Laser scanning on road pavements: a new approach for characterizing surface texture. Sensors, 12(7): 9110-9128.

ChIn, A., 2012. Paving the way for terrestrial laser scanning assessment of road quality. MSc dissertation, Oregon State University, USA. 127 pages.

Collins, R., 2007. Robust estimation: RANSAC. http://www.cse.psu.edu/rrcollins/CSE486/lecture15_6pp.pdf [Accessed: 10th March 2012]. 
KUMAR et al. An algorithm for automated estimation of road roughness from mobile laser scanning data

Davies, R. B., Cenek, P. D. and Henderson, R. J., 2005. The effect of skid resistance and texture on crash risk. Proceedings of International Conference on Surface Friction - Roads and Runways, Christchurch, New Zealand. 17 pages.

Derpanis, K. G., 2010. Overview of the RANSAC algorithm. http://www.cse.yorku.ca/ Kosta/CompVis_Notes/ ransac.pdf [Accessed: 12th February 2012].

Diaz, J. C. F., Judge, J., Slatton, K. C., Shrestha, R., Carter, W. E. and Bloomquist, D., 2010. Characterization of full surface roughness in agricultural soils using groundbased LiDAR. IEEE International Geoscience and Remote Sensing Symposium (IGARSS), Honolulu, Hawaii, USA. 4442-4445.

ETSC, 1997. Road safety audit and safety impact assessment. http://www.etsc.eu/oldsite/roadaudit.pdf [Accessed: 15th December 2011].

FARiAs, M. M. DE and DE SouzA, R. O., 2009. Correlations and analyses of longitudinal roughness indices. Road Materials and Pavement Design, 10(2): 399-415.

Fischler, M. A. and Bolles, R. C., 1981. Random sample consensus: a paradigm for model fitting with applications to image analysis and automated cartography. Communications of the ACM, 24(6): 381-395.

Hollaus, M. and HöFle, B., 2010. Terrain roughness parameters from full-waveform airborne LiDAR data combination of object-based image and point cloud analysis. International Archives of Photogrammetry, Remote Sensing and Spatial Information Sciences, 38(7B): 287-292.

IHs, A., 2004. The influence of road surface condition on traffic safety and ride comfort. Proceedings of 6th International Conference on Managing Pavements, Brisbane, Australia. 11 pages.

IRF, 2003. Safe mobility: an IRF discussion paper. http://www.irfnet.org [Accessed: 29th November 2011].

Kertesz, I., Lovas, T. and BArsi, A., 2007. Measurement of road roughness by low-cost photogrammetric system. International Archives of Photogrammetry, Remote Sensing and Spatial Information Sciences, 36(5/C55). 4 pages.

Kumar, P., 2012. Road features extraction using terrestrial mobile laser scanning system. Doctoral thesis, National University of Ireland Maynooth, Ireland. 300 pages.

Kumar, P., McElhinney, C. P., Lewis, P. and McCarthy, T., 2013. An automated algorithm for extracting road edges from terrestrial mobile LiDAR data. ISPRS Journal of Photogrammetry and Remote Sensing, 85: 44-55.

Kumar, P., McElhinney, C. P., Lewis, P. and McCarthy, T., 2014. Automated road markings extraction from mobile laser scanning data. International Journal of Applied Earth Observation and Geoinformation, 32: $125-137$.

PAterson, W. D. O., 1987. Road deterioration and maintenance effects: models for planning and management. Johns Hopkins University Press, Maryland, USA. 472 pages.

Pattnaik, S. B., Hallmark, S. and Souleyrette, R., 2003. Collecting road inventory using LIDAR surface models. Proceedings of Map India Conference, New Delhi, India. 7 pages.

Sayers, M. W., Gillespie, T. D. and Queiroz, C. A. V., 1986. The international road roughness experiment. World Bank Technical Paper WT45, Washington, DC, USA. 468 pages.

Sayers, M. and Karaminas, S. M., 1998. The little book of profiling. http://www.umtri.umich.edu/content/ LittleBook98R.pdf [Accessed: 15th March 2012].

Treat, J. R., Tumbas, N. S., McDonald, S. T., Shinar, D., Hume, R. D., Mayer, R. E., Stansifer, R. L. and CAstellan, N. J., 1979. Tri-level study of the causes of traffic accidents. http:// deepblue.lib.umich.edu/handle/2027.42/64993 [Accessed: 10th February 2012].

WEN, W., 2008. Road roughness detection by analysing IMU data. MSc dissertation, Royal Institute of Technology, Stockholm, Sweden. 101 pages.

Yen, K. S., Akin, K., Lofton, A., Ravani, B. and Lasky, T. A., 2010. Using mobile laser scanning to produce digital terrain models of pavement surfaces. http://ahmct.ucdavis.edu/pdf/UCD-ARR-10-11-3001.pdf [Accessed: 3rd July 2012].

Yu, S.-J., Sukumar, S. R., Koschan, A. F., Page, D. L. and Abidi, M. A., 2007. 3D reconstruction of road surfaces using an integrated multi-sensory approach. Optics and Lasers in Engineering, 45(7): 808818.

Zhang, A. M. and Russell, R. A., 2004. Surface roughness measurement for outdoor mobile robotic applications. Proceedings of Australasian Conference on Robotics and Automation, Canberra, Australia. 6 pages.

ZhANG, K. and FreY, H. C., 2005. Road grade estimation for on-road vehicle emissions modeling using LIDAR data. Proceedings of Air \& Waste Management Association Annual Meeting, Minneapolis, USA. 22 pages. 


\section{Résumé}

La rugosité d'une route est la déviation de la surface de la route par rapport à la surface conçue, qui influence les conditions de sécurité pour les usagers de la route. Le balayage laser mobile (MLS) offre un moyen rapide, continu et rentable pour recueillir des nuages de points $3 D$ très précis et denses le long d'une route. Cet article présente un algorithme pour l'estimation automatique de la rugosité de la route à partir de données MLS, où une grille est ajustée sur les points lidar censés représenter la surface de la route. La différence entre les altitudes des points lidar et de leurs équivalents dans la grille fournit des valeurs résiduelles de hauteur qui peuvent être utilisées pour estimer la rugosité à la surface de la route. Des tests ont validé ce nouvel algorithme en estimant les caractéristiques de la surface sur de multiples sections de route. Ces résultats contribuent à une approche plus globale du relevé topographique des réseaux routiers.

\section{Zusammenfassung}

Die Rauhigkeit einer Strassenoberfläche ist die qualitative Abweichung der tatsächlichen Oberfläche von der geplanten Oberfläche. Eine solche Abweichung beeinflußt die Sicherheitsbedingungen für Straßennutzer. Mit Mobile Laserscanning Systemen (MLS) können schnell, kontinuierlich und auf kostengünstige Weise hochgenaue und dichte 3D-Punktwolken entlang eines Straßenkorridors erfasst werden. Dieses Paper stellt einen Algorithmus zur automatischen Bestimmung der Oberflächenrauhigkeit in MLS Daten vor. Ein Oberflächenraster wird an die Punkte der Straßenoberfäche angepasst. Die Residuen zwischen Lidarpunkten und den entsprechenden Höhen des angepaßten Gitters können zur Schätzung der Rauhigkeit verwendet werden. In Tests mit verschiedenen Straßenabschnitten wurde der neue Algorithmus hinsichtlich der Schätzung der Oberflächenbeschaffenheit validiert. Auf Basis dieser Ergebnisse kann ein noch umfassender Ansatz zur Erfassung von ganzen Straßennetzen angegangen werden.

\section{Resumen}

La rugosidad de una carretera es la desviación de la superficie diseñada que afecta las condiciones de seguridad de los usuarios de la carretera. Los sistemas de láser móviles proporcionan una manera rápida, continua y barata de recolectar nubes de puntos 3-D densas y de gran precisión a lo largo de un corredor. En este artículo se presenta un algoritmo para la estimación automática de la rugosidad de la carretera, dónde una malla se ajusta a los puntos lídar asociados con la superficie de la carretera. La diferencia entre la elevación de los puntos lídar y los equivalentes en la malla proporcionan residuos en altura usados para estimar la rugosidad de la superficie a lo largo de la carretera. Las comprobaciones validan el nuevo algoritmo de rugosidad de la carretera al estimar con éxito las condiciones de la carretera en diversas secciones de carretera. Estos resultados contribuyen a un enfoque más amplio de la medida de las características de redes de carreteras.

\section{摘要}

路面平整度是衡量道路表面和设计表面之差的等级,对道路使用者的安全条件的度量。移动激光扫描 $(M L S)$ 系统提供了一种快速获取低成本、高精确和高密度的沿着路线走廊的连续三维点云数据的方式。本 文提出从MLS数据自动估计路面平整度的算法, 该算法利用一个路面格网来拟合激光点云, 两者之间在高程 上的残差值可以被用来衡量路面平整度。试验充分验证了本文所提出的新算法针对多路段路面平整度处理 的可靠性,本文的这些发现为路网测量提供了一种更全面的手段。 